\title{
Riscos \\ Psicossociais e Incapacidade do Servidor Público: Um Estudo de Caso
}

Psychosocial Risks And Incapacity Of The Civil Servant: A Case Study

Psicosociales E Incapacidad Del Funcionario Público: Un Estudio De Caso
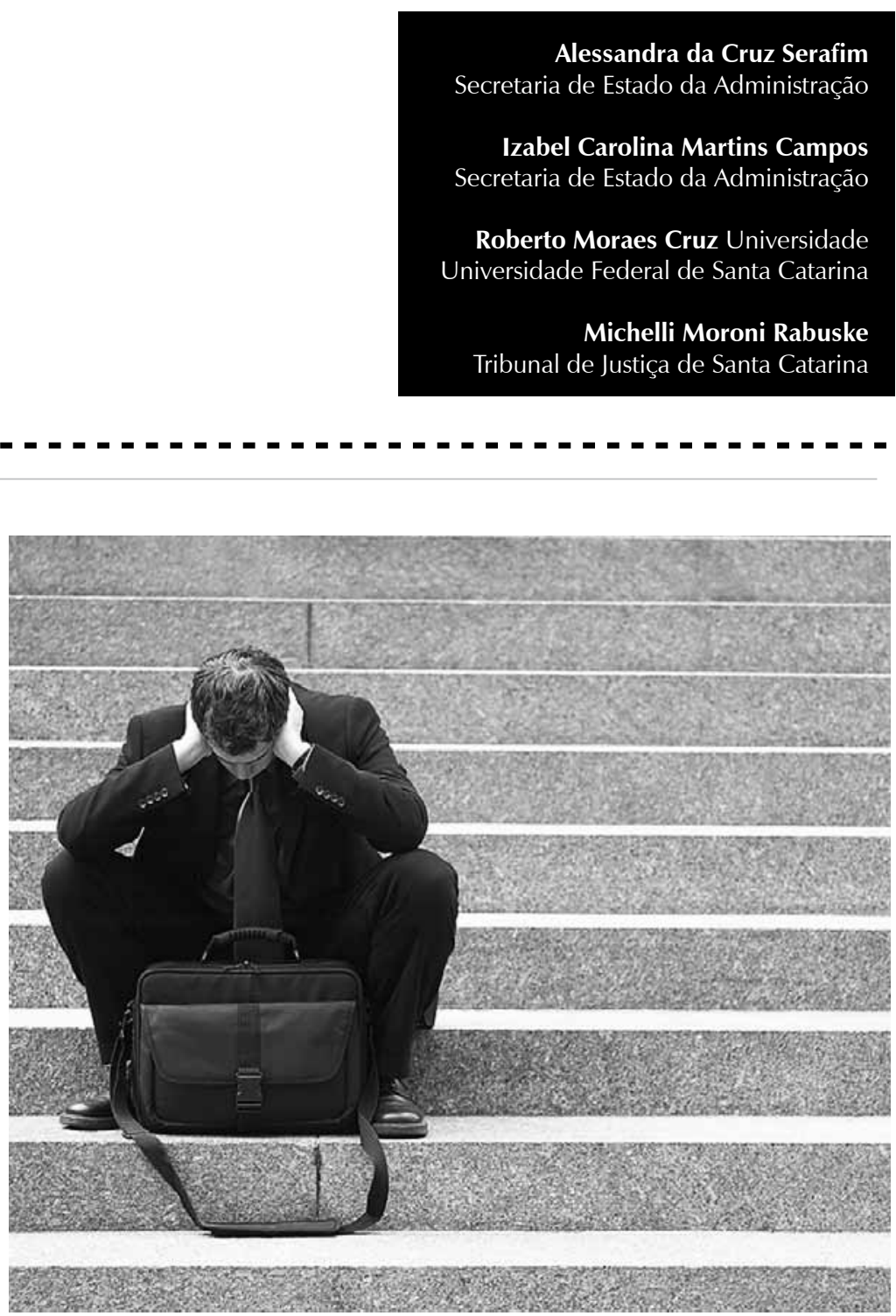
Resumo: Os fatores de risco psicossociais do trabalho (FRPT), como o estresse, as pressões patogênicas da carga de trabalho, as dificuldades nas relações socioprofissionais e as condições e a organização inadequadas do trabalho podem ser consideradas variáveis que interferem na saúde mental e física do trabalhador. A prevenção desses aspectos deve ocorrer por meio da sensibilização, conscientização, motivação e ação organizada dos atores sociais da empresa ou do órgão. Os servidores públicos estaduais de Santa Catarina estão submetidos aos FRPT, e há relações entre estes e o adoecimento relacionado ao trabalho. Este artigo parte de um estudo de caso, por meio de análise documental relativa à perícia psicológica para a caracterização de acidente em serviço/doença referente ao trabalho no ano 2008. O estudo de caso demonstrou que a exposição da servidora ao longo de sua vida laborativa aos FRPT - sobrecarga cognitiva e psíquica, ritmo intenso, longas jornadas e precárias condições de trabalho - foram os fatores que desempenharam papel preponderante na ocorrência da incapacitação para o trabalho. Concluiu-se que os FRPT devem ser considerados nas avaliações dos casos de adoecimento e incapacidade profissional, bem como na implementação dos dispositivos legais catarinenses que se referem à promoção da saúde ocupacional dos servidores dos órgãos do Poder Executivo estadual.

Palavras-chave: Fatores psicossociais. Saúde ocupacional. Doenças ocupacionais. Stress ocupacional. Qualidade de vida no trabalho

Abstract: The psychosocial risk factors of work (FRPT), as pathogenic pressure, stress, workload, socioprofessional relations difficulties and inadequate conditions and work organization can be considered variables that interfere in the mental and physical health of the employee. The prevention of these aspects must occur through awareness, motivation and organized action of the social actors in the organization. Santa Catarina's civil servants are subjected to FRPT and there are relations between these FRPT and work-related illness. This article is part of a case study, through documentary analysis concerning psychological expertise for the characterization of accident in service/work-related illness in 2008. The case study showed that the exposure of the employee throughout her labor life to FRPT - related to cognitive and mental overload, intensive pace, long workdays and precarious working conditions - were the factors that played the major role in the occurrence of incapacitation to work. It was concluded that the assessments shall consider FRPT in cases of illness and disability, as well as in the implementation of the legal provisions related to the protection of the civil servants occupational health in the executive power of the state.

Keywords: Psychosocial factors. Occupational health. Occupational diseases. Occupational stress. Quality of work life.

Resumen: Los factores de riesgo psicosociales del trabajo (FRPT), como el estrés, las presiones patogénicas de la carga de trabajo, las dificultades en las relaciones socio-profesionales y las condiciones y la organización inadecuadas del trabajo pueden ser consideradas variables que interfieren en la salud mental y física del trabajador. La prevención de esos aspectos debe ocurrir por medio de la sensibilización, concientización, motivación y acción organizada de los actores sociales de la empresa o del órgano. Los funcionarios públicos estatales de Santa Catarina están sometidos a los FRPT, y hay relaciones entre éstos y el padecimiento relacionado al trabajo. Este artículo parte de un estudio de caso, por medio de análisis documental relativa a la pericia psicológica para la caracterización de accidente en servicio/dolencia referente al trabajo en el año 2008. El estudio de caso demostró que la exposición de la funcionaria a lo largo de su vida laboral a los FRPT - sobrecarga cognitiva y psíquica, ritmo intenso, largas jornadas y precarias condiciones de trabajo - fueron los factores que desempeñaron papel preponderante en la ocurrencia de la incapacitación para el trabajo. Se concluyó que los FRPT deben ser considerados en las evaluaciones de los casos de enfermedad y de incapacidad profesional, así como en la implementación de los dispositivos legales del Estado de Santa Catarina que se refieren a la promoción de la salud ocupacional de los funcionarios de los órganos del Poder Ejecutivo estadual.

Palabras clave: Factores psico-sociales. Salud ocupacional. Enfermedades ocupacionales. Estrés ocupacional. Calidad de vida en el trabajo.

Em 1986, a Organização Internacional do Trabalho (OIT) definiu risco psicossocial como a interação entre o conteúdo do trabalho, a sua organização e o seu gerenciamento, com outras condições ambientais e organizacionais, por um lado, e as competências e as necessidades dos trabalhadores de outro.
Para Guimarães (2006), os fatores de risco psicossociais do trabalho (FRPT) são definidos como aquelas características do trabalho que funcionam como estressores, ou seja, que implicam grandes exigências do posto de trabalho, combinadas com recursos insuficientes internos do trabalhador para 
o seu enfrentamento. Os FRPT podem ser também entendidos como as percepções subjetivas que o trabalhador tem (exigências das características físicas da carga, da personalidade do indivíduo, das experiências anteriores e da situação social do trabalho) dos fatores de organização do trabalho: carreira, cargo, ritmo, ambiente social e técnico.

A incapacidade laborativa pode ser compreendida, de acordo com a Resolução do Instituto Nacional de Seguridade Social (INSS /DC no. 10, 1999), como "a impossibilidade do desempenho das funções específicas de uma atividade (ou ocupação), em conseqüência de alterações morfopsicofisiológicas provocadas por doença ou acidente (...)". No serviço público estadual de Santa Catarina, conforme previsão legal estadual, a incapacidade para o trabalho gera a concessão de licença para tratamento de saúde (LTS), restrição de tarefas, readaptação, remoção, aposentadoria e acidente em serviço.

Os FRPT não estão discriminados detalhadamente na legislação brasileira e não são considerados, na análise do posto de trabalho, da mesma forma que os fatores de risco físicos, mecânicos, biológicos, químicos e ergonômicos previstos nas Normas Regulamentadoras (NRs) do Ministério do Trabalho e Emprego. A exposição ocupacional aos FRPT apresenta consequências diretas nas condições de saúde dos trabalhadores, podendo gerar adoecimento, incapacidade laborativa e repercussões na vida social e familiar.

Com relação à exposição ocupacional aos FRPT no serviço público, Campos (2006) analisou o perfil do servidor público do Estado de Santa Catarina e as associações com o adoecimento psicológico e as características laborativas, no período de 2001 a 2005, em servidores da área da saúde, educação, segurança pública e administração. O estudo demonstrou as influências das características laborativas na incidência de depressão, estresse e patologias do sistema osteomuscular nos servidores que se afastaram do serviço por LTS nesse período. Essas doenças foram relacionadas aos FRPT, tais como: as condições de trabalho, seu modo de funcionamento e sua organização degradados, as relações sociais, a sobrecarga de trabalho, o ritmo, as demandas ligadas à alternância da gestão política no poder, a baixa remuneração e as longas jornadas, dentre outros.

O objetivo deste artigo é analisar os FRPT aos quais estão submetidos os servidores públicos estaduais em Santa Catarina, bem como as relações entre os FRTP, o adoecimento relacionado ao trabalho e as estratégias de prevenção. Diante da centralidade do trabalho na vida do indivíduo e das especificidades do processo de trabalho no serviço público, uma questão se impõe: os riscos psicossociais do trabalho podem gerar incapacidade para o servidor público?

\section{Fatores de risco psicossociais do trabalho (FRPT)}

Trivelato (1998) caracteriza situação ou fator de risco como a probabilidade de um resultado adverso ou prejuízo como morte, lesões, doenças e danos à saúde, ao homem, ao meio ambiente e à propriedade. Segundo Sauter, Hurrell Jr., Murphy e Levi (2002), os FRPTs podem ser compreendidos como as condições do trabalho que podem conduzir ao estresse, e estão relacionadas aos aspectos do posto de trabalho, do seu entorno, do clima e da cultura organizacional, das funções laborativas, das relações interpessoais entre colegas, do desenho e do conteúdo das tarefas. As relações entre os fatores psicossociais presentes no ambiente da 
organização e nas características do indivíduo relativas a sua história de vida e as suas relações familiares e sociais podem repercutir na eclosão do estresse no contexto laboral.

A Norma Técnica de Prevenção (NTP no 443, 1994) do Ministério do Trabalho e Assuntos Sociais da Espanha define os FRPT como as condições que estão presentes no contexto laboral e que estão diretamente relacionadas à organização, ao conteúdo do trabalho e à realização das tarefas, e que têm a capacidade de afetar tanto o bem-estar como a saúde física, psíquica e social do trabalhador no desenvolvimento de suas atividades. Sendo assim, a exposição do trabalhador a condições psicossociais adversas pode prejudicar a sua saúde e o seu bem-estar e gerar sofrimento psíquico, sentimentos de insatisfação e desmotivação no trabalho e problemas de relacionamento, entre outras dificuldades.

Segundo essa mesma NTP, diante de determinadas condições psicossociais adversas, nem todos os trabalhadores desenvolverão as mesmas reações. Certas características próprias da personalidade de cada trabalhador, associadas às suas expectativas, vulnerabilidades, capacidade de adaptação e recursos de enfrentamento diante de estressores, determinarão a magnitude e a natureza tanto das suas reações como das consequências que sofrerão. Os fatores de risco psicossociais precisam ser compreendidos tanto como as condições que se apresentam de forma objetiva no contexto laboral como as que são percebidas e experienciadas pela pessoa.

Guimarães (2006) categoriza os riscos psicossociais em dois tipos: estressores ou demandas de trabalho e disponibilidade de recursos pessoais e laborais. O primeiro refere-se às dimensões físicas, sociais e organizacionais que exigem manutenção do esforço e que estão ligadas aos custos psicológicos e fisiológicos no processo de trabalho, como, por exemplo, a sobrecarga quantitativa ou o conflito de papéis. O segundo tipo, a existência de recursos pessoais e laborais, corresponde aos aspectos psicológicos, físicos, sociais e organizacionais que são necessários para a obtenção das metas, que minimizam as demandas laborais e estimulam o desenvolvimento profissional. A mesma autora sustenta que há duas espécies de recursos: pessoais e laborais. Os recursos pessoais dizem respeito às características das pessoas, como a autoeficácia profissional. Os recursos do contexto laboral estão relacionados com o nível de autonomia no trabalho, o feedback sobre as atividades desenvolvidas e a capacitação que a organização oferece ao trabalhador.

Os fatores inerentes ao trabalho, de acordo com a OIT (2002), são o ajuste pessoaentorno, a carga, a jornada, o desenho do ambiente físico, a autonomia, o controle, o ritmo, a supervisão eletrônica do trabalho, a transparência de papéis, a sobrecarga de funções e os fatores ergonômicos. A forma como esses fatores estão dispostos e combinados influenciarão de forma significativa a saúde dos trabalhadores.

Os fatores de risco psicossociais apresentam relação com as condições, a organização e as relações sociais de trabalho. Condições de trabalho são "as pressões físicas, mecânicas, químicas e biológicas do posto de trabalho. As pressões ligadas às condições de trabalho têm por alvo principal o corpo dos trabalhadores, onde elas podem ocasionar desgaste, envelhecimento e doenças somáticas" (Dejours \& Abdoucheli, 1990/1993, p.125). Além disso, as condições de trabalho compreendem elementos estruturais, os quais estão "presentes no lócus de produção e caracterizam sua infra-estrutura, apoio institucional e práticas administrativas" 
(Ferreira \& Mendes, 2003, p. 42). Esses elementos estruturais são o ambiente físico, os instrumentos, os equipamentos, a matériaprima, o suporte organizacional, as práticas de remuneração, o desenvolvimento de pessoal e os benefícios.

Dejours \& Abdoucheli definem a organização do trabalho como "a divisão do trabalho: divisão de tarefas entre os operadores, repartição, cadência e, enfim, o modo operatório prescrito, e, por outro lado, a divisão de homens: repartição das responsabilidades, hierarquia, comando, controle, etc." (1990/1993, p. 125). Segundo Ferreira e Mendes (2003), a organização do trabalho é formada pelos elementos prescritos (formal ou informalmente) que manifestam as concepções e a gestão de pessoas e do trabalho existentes no lócus de produção. Os componentes dessa dimensão são a divisão do trabalho, a produtividade esperada, as regras formais, o tempo, os ritmos, os controles e as características das tarefas.

As relações sociais de trabalho são formadas pelos componentes que expressam as relações socioprofissionais de trabalho presentes no lócus de produção, caracterizando sua dimensão social. Os elementos que integram essa dimensão são as interações hierárquicas, as interações coletivas intra e intergrupos e as interações externas (Ferreira \& Mendes, 2003).

As condições, a organização e as relações sociais de trabalho são indicadores que exercem papel fundamental para a saúde dos trabalhadores, de acordo com o confronto entre os trabalhadores e o seu contexto de trabalho. Os aspectos desse confronto contribuem para ocorrência de vivências de bem-estar ou de mal-estar dos trabalhadores e de riscos de adoecimento.

\section{Estresse ocupacional e agentes psicossociais estressores}

No estudo dos FRPTs, o estresse ocupacional aparece de forma constante, tendo em vista que ele é produto desses riscos psicossociais existentes no contexto laborativo. BenevidesPereira (2002) demonstra que, quando o agente desencadeador do adoecimento se refere à atividade desempenhada, o trabalhador será reportado ao estresse ocupacional.

Paschoal e Tamayo conceituam estresse ocupacional como "um processo em que o indivíduo percebe demandas do trabalho como estressores, os quais, ao exceder sua habilidade de enfrentamento, provocam no sujeito reações negativas" (2004, p. 46). Para que fatores organizacionais sejam encarados como estressores pelo trabalhador, ele precisa identificá-los como tal. Os autores classificam os estressores organizacionais em natureza física - ruído, iluminação, ventilação e outros - e psicossocial - aspectos do relacionamento interpessoal no trabalho, fatores intrínsecos ao trabalho e ao desenvolvimento da carreira, autonomia e controle no trabalho e estressores baseados em papéis.

Segundo Jacques (2003), a teoria sobre o estresse é uma das abordagens que estuda a relação entre saúde mental e trabalho, configurando-se como um conjunto de várias teorias que estudam o estresse. A teoria privilegia a utilização de métodos quantitativos de avaliação de fatores estressores, coping ou estresse propriamente dito e o emprego de pressupostos teóricos do referencial cognitivocomportamental, atribuindo ao trabalho o fator desencadeante do processo do estresse, em maior ou menor grau de relevância.

O estresse ocupacional está associado à incapacidade do trabalhador para enfrentar 
Segundo Levi (2002), o estresse

psicossocial

no trabalho tem por causa uma deficiente adaptação entre a pessoa e o seu contexto laboral, levando em consideração os outros meios sociais e os componentes individuais. as demandas laborativas e a consequente vivência de mal-estar e sofrimento. Quando os fatores psicossociais incidem de forma contundente, além das capacidades de adaptação do indivíduo, surge o enrijecimento muscular e a exaustão psicológica. Segundo Schibuola (2005), os sintomas e os quadros clínicos associados são cefaleia tensional, tensão muscular, taquicardia, cardiopatias, depressão, burnout e distúrbios músculoesqueléticos, entre outros.

Segundo Levi (2002), o estresse psicossocial no trabalho tem por causa uma deficiente adaptação entre a pessoa e o seu contexto laboral, levando em consideração os outros meios sociais e os componentes individuais. $\mathrm{O}$ estresse acontece quando as exigências do meio não correspondem à capacidade individual de adaptação, ou quando as oportunidades que o ambiente oferece não estão à altura das necessidades e expectativas do indivíduo. Todo ajuste ou adaptação dependerá tanto de fatores situacionais como das características individuais e do grupo. De acordo com a mesma autora e com Oliveira (2002), os principais fatores situacionais que influenciam no surgimento do estresse são a sobrecarga quantitativa, a insuficiente carga qualitativa, os conflitos de papéis, a falta de controle sobre a situação pessoal, a falta de apoio social e os estressores físicos. Esses fatores, muitas vezes, interagem, contribuindo de forma multideterminada para o aumento do estresse e o adoecimento do trabalhador.

Santos, Goulart Junior, Canêo, Lunardelli, e Carvalho (2010) realizaram pesquisa bibliográfica sobre neurose profissional, psicopatologia associada diretamente às condições de trabalho, cujos sintomas são compreendidos como a expressão simbólica de um conflito psíquico que se estabelece por meio de situações organizacionais ou profissionais determinadas. Os autores constataram que há associação significativa entre essa doença e o estresse ocupacional, sendo que a constante submissão do trabalhador aos estressores ocupacionais podem ocasionar a neurose profissional, que se configura como um estado de desorganização persistente da personalidade.

Noronha e Fernandes (2006) pesquisaram as relações existentes entre o estresse laboral e o raciocínio inferencial, sexo e idade, por meio da aplicação do Teste de Raciocínio Inferencial - RIn - e a Escala de Vulnerabilidade a Estressores no Trabalho - EVET em 64 estudantes universitários de uma instituição privada. Os autores verificaram que, quanto maior for a vulnerabilidade ao nível de estresse da pessoa, menor será sua capacidade do raciocínio inferencial, como também, consoante o aumento da vulnerabilidade em relação à falta de suporte organizacional, menor a pontuação do Rln. Em relação à diferença com significância estatística entre os sexos, constataram que as mulheres mostraram-se mais vulneráveis que os homens em relação ao suporte organizacional. Sobre a idade, observaram que as pessoas com maior idade tendem a ter maior vulnerabilidade ao estresse no trabalho.

O modelo demanda-controle-apoio social, de Karasek (2002), analisa as situações laborativas relacionadas às características psicossociais do trabalho que funcionam como predisposição para o risco de adoecimento. De acordo com os autores, as três variáveis desse modelo podem ser compreendidas como demandas psicológicas, controle e apoio social. As demandas psicológicas são as exigências do trabalho, como a quantidade e o volume do trabalho, a pressão do tempo, o nível de atenção, as interrupções previstas e outros. O controle compreende a autonomia, como possibilidade de a pessoa poder influenciar nas decisões relacionadas ao trabalho e de controlar suas próprias atividades, e o 
desenvolvimento de habilidades, tais como aprendizagem, criatividade e atividades de trabalho variadas. O apoio social refere-se ao clima social no trabalho e à relação existente entre os colegas e os superiores, tendo a função de moderar os estressores no contexto de trabalho.

Esse modelo preconiza que o desequilíbrio entre as demandas e as respostas do indivíduo e a precariedade do nível de apoio social conduzem ao estresse e ao risco de patologias nos trabalhadores. A combinação das variáveis demanda psicológica e atitude na tomada de decisões gera quatro situações psicossociais que repercutem na saúde e no comportamento: a) trabalho com elevados níveis de exigências e escassa capacidade de controle: o trabalhador está exposto a alta tensão, o que o conduz a um risco elevado de estresse e de enfermidades de diversas ordens, b) trabalho com baixo grau de demanda e alto grau de controle: há baixo nível de tensão, e o indivíduo está em uma situação parecida com o de relaxamento, c) trabalho com exigências elevadas e alto nível de controle: o trabalhador encontrase ativo, em uma situação de estresse positivo, que gera maiores possibilidades de aprendizagem, motivação e desenvolvimento pessoal, d) trabalho com baixo grau de demanda e reduzida autonomia: tipo de trabalho passivo, desmotivador, com pouco potencial de aprendizagem, que representa risco potencial a patologias (Karasek, 2002). Nesse sentido, trabalhadores que estão submetidos a alta tensão e ao tipo de trabalho passivo apresentam maior predisposição ao estresse e ao adoecimento, mas a correlação com a variável apoio social indica que, quanto maior o nível de apoio existente entre os colegas de trabalho e os gestores, maior é a probabilidade de os trabalhadores reduzirem a estimulação do sistema nervoso central, o que protegeria a sua saúde.
Verifica-se, na literatura nacional, que os estudos relacionados a saúde/doença em profissionais de saúde têm privilegiado os enfermeiros e os médicos, principalmente em contexto hospitalar, não sendo encontradas pesquisas pertinentes a saúde mental e trabalho, específicas para servidores que desempenham atividades administrativas em hospitais, conforme o estudo de caso do presente artigo.

Araujo, Aquino, Menezes, Santos, e Aguiar, (2003) realizaram estudo de corte transversal em 502 trabalhadoras de enfermagem em um hospital público de Salvador, utilizando metodologia do modelo demanda-controle, de Karasek (2002), para análise das dimensões psicossociais, e o SRQ-20 para avaliação dos distúrbios psíquicos menores (DPM). Os autores constataram que $33,3 \%$ das trabalhadoras apresentavam DPM, a existência de associação positiva entre demanda psicológica e DPM, e associação negativa entre controle do trabalho e DPM, sendo que, no quadrante de trabalho que apresentava alta exigência (caracterizado por alta demanda e baixo controle), a prevalência de DPM foi mais alta em relação às funcionárias em trabalho com baixa exigência (caracterizado por baixa demanda e alto controle).

Nascimento Sobrinho et al. (2006) realizaram estudo epidemiológico de corte transversal com uma amostra aleatória de 350 médicos na cidade de Salvador e verificaram que os médicos estavam submetidos a elevada sobrecarga de trabalho, a numerosas horas de trabalho em sistema de plantão, a inúmeras inserções, a contratação instável com remuneração por procedimento e a baixa remuneração. Em relação às queixas de saúde, prevaleceram as relacionadas aos transtornos mentais e posturais. Os distúrbios psiquiátricos menores obtiveram a prevalência de $26 \%$. 
Pinho e

Araújo (2007)

analisaram,

em 80

profissionais de

enfermagem,

no setor de

emergência

de um hospital

da Bahia,

a presença

dos TMC e

os aspectos

psicossociais

do trabalho

relacionando-os

ao adoecimento

desses

trabalhadores.
Cabana, Ludemir, Silva, Ferreira, e Pinto (2007) efetuaram estudo de prevalência com a utilização de um questionário sobre o cotidiano de trabalho do médico e o SRQ20, com o objetivo de comparar o cotidiano de trabalho e a prevalência dos transtornos mentais comuns (TMC) dos médicos que trabalhavam no setor de emergência com os da UTI e os das enfermarias de um hospital estadual de Recife. Todos os médicos dos três setores citaram sobrecarga de trabalho, e grande parte dos que atuavam em terapia intensiva e emergência tinha vários empregos, com longa jornada semanal. Os médicos que trabalhavam na emergência mantinham carga horária semanal superior a 70 horas, e afirmaram que o seu trabalho causava sofrimento. Os pesquisadores verificaram que a emergência era o setor onde prevalecia os TMC, com médicos que exerciam atividades laborativas em piores condições de trabalho e que usavam a impessoalidade e a frieza afetiva ao lidar com os pacientes como mecanismos psíquicos de defesa.

Pinho e Araújo (2007) analisaram, em 80 profissionais de enfermagem, no setor de emergência de um hospital da Bahia, a presença dos TMC e os aspectos psicossociais do trabalho relacionando-os ao adoecimento desses trabalhadores. Foi utilizado um questionário sobre condições sociodemográficas e características do trabalho, sendo que as características psicossociais do trabalho foram obtidas por meio do JCQ, e a saúde mental, do SRQ-20. Constatou-se que há uma relação entre o trabalho realizado e a saúde do trabalhador, com ligação positiva entre trabalho de alta exigência e os TMC.

Braga, Carvalho, e Binder (2010) realizaram um estudo transversal e descritivo em 378 trabalhadores da rede básica de saúde de Botucatu (SP), com o objetivo de analisar a associação entre demandas psicológicas, grau de controle e presença de suporte social no trabalho como também a prevalência de TMC nesses trabalhadores. Os autores identificaram que $42 \%$ dos trabalhadores apresentavam TMC, com alta prevalência de TMC em atividades com elevado desgaste e baixa prevalência de TMC com baixo desgaste. Trabalhadores com funções que exigiam nível médio de escolaridade apresentaram 46\% de TMC, e, os profissionais que exerciam atividades de nível superior, 34\%. Segundo Braga et al., as condições de trabalho na Atenção Básica do Município estudado constituem fator contributivo que não pode ser negligenciado no adoecimento dos trabalhadores.

Consoante Secco, Robazzi, Souza, Alves e Shimizu (2010), é complexa a caracterização do acidente em serviço ou da doença relacionada ao trabalho, tendo em vista o número das variáveis existentes nesse processo, tais como: o envelhecimento natural do trabalhador, os componentes históricos e sociais do indivíduo, os hábitos de vida, a maneira como é desenvolvido o processo de trabalho e o contexto em que ocorre. Os agravos de ordem emocional apresentam dificuldades maiores para ter $\mathrm{o}$ seu nexo causal estabelecido, uma vez que se instalam de forma insidiosa no trabalhador, principalmente devido às cargas de trabalho psíquicas. Segundo os autores, as cargas psíquicas constituem o estresse no trabalho advindo do ritmo e da intensidade laboral, da necessidade de manter-se sempre atualizado, em condições de competir no mercado de trabalho, das relações de poder com chefias, do processo de organização e de divisão das tarefas, das exigências peculiares da atividade exercida e outros.

Secco et al. (2010) investigaram a relação das cargas psíquicas de trabalho existente na organização de trabalho de sete gerentes 
de enfermagem em um hospital de ensino do Paraná e o desgaste dos profissionais decorrente dessa exposição. Os pesquisadores constataram que as cargas psíquicas às quais esses trabalhadores estão submetidos sofrimento em relação à finitude da vida, baixa remuneração, envelhecimento dos profissionais, mais de uma jornada de trabalho, acúmulo de atividades domésticas, pouco reconhecimento da profissão, baixa autonomia e número reduzido de trabalhadores para atender a demanda, entre outros fatores - contribuem para a eclosão de distúrbios emocionais que interferem de forma significativa na vida do trabalhador.

\section{A saúde do servidor público estadual em Santa Catarina e a caracterização de acidentes em serviço}

A Secretaria de Estado da Administração (SEA) é responsável pela execução das atividades periciais e da gestão da sua saúde ocupacional dos servidores públicos estaduais do Poder Executivo do Estado de Santa Catarina. Ambas as atividades são desenvolvidas no Centro de Saúde do Servidor, sendo que a primeira delas cabe à Gerência de Perícia Médica (GEPEM) e a outra, à Gerência de Saúde Ocupacional (GESAO). A Perícia Médica Oficial do Estado surgiu em 1978, e a GESAO, no final de 2005. Com a criação dessa gerência, ampliou-se a perspectiva do campo de atuação relacionado às atividades de saúde ocupacional do Estado por meio da inclusão de novos profissionais. Atualmente, a equipe conta com médico do trabalho, enfermeiro do trabalho, engenheiro de segurança do trabalho, técnico de segurança do trabalho, técnico de enfermagem do trabalho, psicólogo e assistente social.

De acordo com o Boletim Estatístico de Saúde do Servidor (2008), no período de janeiro a dezembro de 2007, considerandose os servidores lotados nos diversos órgãos do Estado e a classificação de diagnósticos realizada com base no Código Internacional de Doenças (CID 10), 29\% dos servidores obtiveram LTS devido a transtornos mentais e comportamentais. Quanto aos demais diagnósticos, $18 \%$ dos servidores foram afastados em LTS por doenças do sistema osteomuscular.

Segundo Cunha, Blank e Boing (2009), considerando o período de 1995 a 2005, dos servidores públicos da Secretaria de Estado da Saúde (SES) que se afastaram do trabalho por problemas de saúde, os principais motivos, em ordem decrescente, que desencadearam as LTS foram os transtornos mentais e comportamentais (TMC) e as doenças do sistema osteomuscular e do tecido conjuntivo, fatores que influenciam o estado de saúde e o contato com os serviços de saúde e outros. Os TMC representaram $25,30 \%$ dos afastamentos, seguidos respectivamente por $20,54 \%$ e $15,19 \%$ das LTS.

O Ministério da Saúde indica que os aspectos do trabalho que contribuem para a ocorrência do adoecimento devem ser considerados. Trata-se da "exposição a determinado agente tóxico, até a complexa articulação de fatores relativos à organização do trabalho, como a divisão e o parcelamento das tarefas, as políticas de gerenciamento das pessoas e a estrutura hierárquica organizacional" (MS, 2001, p.161).

O Decreto no 3.048 (1999) do Ministério da Previdência e Assistência Social apresenta uma lista de doenças profissionais e relacionadas ao trabalho. Dentre os transtornos mentais e do comportamento, caracterizam-se os seguintes diagnósticos: demência em outras doenças específicas classificadas em outros locais, 
delirium, não sobreposto à demência, como descrita, transtorno cognitivo leve, transtorno orgânico de personalidade, transtorno mental orgânico ou sintomático não especificado, alcoolismo crônico relacionado ao trabalho, episódios depressivos, estado de estresse póstraumático, neurastenia, incluindo síndrome de fadiga, outros transtornos neuróticos especificados, incluindo neurose profissional, transtorno do ciclo vigília-sono devido a fatores não orgânicos, sensação de estar acabado, incluindo síndrome de burnout e síndrome do esgotamento profissional.

No serviço público catarinense, não vigora o nexo técnico epidemiológico (NTEP), como ocorre nas relações de trabalho regidas pela Consolidação das Leis do Trabalho. A Lei Federal nำ11.430 (2006) e o Decreto n․ 6.042 (2007), que entraram em vigor em 10 de abril de 2007, regulamentam as transformações na caracterização dos acidentes e das doenças relacionadas ao trabalho pelo processo do nexo técnico epidemiológico. A relação do nexo causal entre o trabalho e o agravo é estabelecida quando se percebe o nexo técnico epidemiológico existente entre a atividade da empresa - Classificação Nacional de Atividade Empresarial (CNAE) - e a doença que originou a incapacidade, configurada pelo CID 10. Quando o trabalhador é afastado por motivo de doença, apresentando um CID compatível com o CNAE estabelecido por esse decreto, automaticamente, o trabalhador receberá o benefício auxílio acidentário.

No Estado de Santa Catarina, conforme o Decreto no. 1.456 (1996), artigo 1으, o acidente em serviço é conceituado como "o dano físico ou mental sofrido pelo servidor que se relacione, mediata ou imediatamente, com o exercício das funções, atividades e atribuições do cargo por ele ocupado". No artigo $2^{\circ}$, equiparam-se ao acidente em serviço a doença profissional e as doenças do trabalho que apresentem nexo causal, ou seja, relação com as atividades desenvolvidas pelo servidor, de acordo com as condições existentes no local de trabalho.

O servidor público do Poder Executivo estadual catarinense possui, portanto, o direito de solicitar avaliação por meio do procedimento de Comunicação de Acidente em Serviço (CEAT) quando considera que sofreu dano de ordem física ou mental que possa ter relação com o trabalho. A caracterização do acidente em serviço é realizada pela equipe da GESAO, considerando-se a avaliação do médico do trabalho, do engenheiro de segurança do trabalho e do psicólogo do trabalho. O parecer técnico a respeito de cada caso resulta da atuação conjunta dos referidos profissionais.

O psicólogo do trabalho atua nos casos das CEATs em que o diagnóstico provável da patologia esteja relacionado a transtornos mentais e comportamentais; sua participação nas referidas avaliações foi iniciada em 2008. A caracterização dos acidentes em serviços relacionados aos transtornos mentais e comportamentais apresenta especificidades de acordo com a área de atuação do servidor, já que o serviço público estadual congrega diferentes áreas - saúde, educação, segurança pública, administração, entre outras - nas quais há diversidade de condições, organização e relações sociais de trabalho.

\section{Método}

Este é um estudo exploratório-descritivo de abordagem qualitativa, e foi realizado por meio de estudo de caso único (Yin, 2005). O caso selecionado representa a situação dos servidores públicos estaduais catarinenses do Poder Executivo que atuam na área da saúde e que vivenciam exposição aos FRPT ao longo de sua vida laborativa. O estudo de caso foi realizado com base nos procedimentos de perícia psicológica para 
caracterização de acidente em serviço que ocorreu em 2008, por meio de análise de documentos - CEAT, relatório do médico assistente, prontuário pericial, prontuário de informações funcionais - e de registros de arquivos - relatórios das entrevistas de avaliação psicológica, protocolos de testes psicológicos, relatórios de vistoria no local de trabalho relativos à observação do posto de trabalho e entrevista psicológica com colegas e chefias imediatas.

No estudo documental do caso, observouse o sigilo e atendeu-se as regulamentações éticas para a pesquisa com seres humanos - Resoluções no 196/96, no 251/97 e no 292/99, do Conselho Nacional de Saúde, e Resolução no 16/2000, do Conselho Federal de Psicologia. Esta pesquisa documental e ex-post facto (realizada posteriormente à ocorrência dos fatos) não foi submetida à apreciação de comitê de ética por ter essas características; além disso, por não estar diretamente vinculada a qualquer universidade e por não haver comitê de ética na SEA. Esclarece-se que o acesso aos prontuários faz parte dos procedimentos periciais e de saúde ocupacional, e que o uso dessas informações é sempre de caráter sigiloso, incluindo-se a publicação de resultados, protegendo-se todos os dados para que não sejam identificados o local de trabalho e o servidor diretamente envolvido na pesquisa. Solicitou-se autorização do supervisor médico da GEPEM/SEA (órgão competente para autorizar a realização da pesquisa e responsável pelos documentos consultados). O estudo destina-se somente a fins científicos, e os registros de todos os detalhamentos sobre saúde e relações profissionais do trabalho do sujeito, constantes no prontuário desta pesquisa, foram tornados públicos sem revelar quaisquer detalhes que identificassem o participante. A aceitação do participante pesquisado foi firmada por meio do seu esclarecimento, sendo ele informado dos objetivos e da realização da pesquisa documental.

\section{Resultados}

O processo de perícia psicológica para caracterização de acidente em serviço foi realizado no primeiro semestre de 2008. Apresentam-se os dados levantados com o estudo de caso sobre a situação de Y, servidora pública, na faixa etária entre 50 e 60 anos, com escolaridade referente ao ensino médio incompleto, lotada em hospital público de grande porte do Estado de Santa Catarina; o serviço público era seu único vínculo empregatício.

$\mathrm{Na}$ análise documental da CEAT, constatouse que o médico assistente considerou que Y apresentava diagnóstico de CID F 33.2, e que redigiu como causa das lesões o seguinte: "Paciente com sintomas do tipo tristeza, desânimo, ansiedade, angústia, ideação suicida, sensível, pouco responsiva à medicação, com períodos de melhora e períodos de piora". Na descrição do acidente, consta que a servidora foi agredida verbalmente e quase fisicamente no local de trabalho, tendo sido ameaçada de morte fora do hospital.

Com relação à história laboral, Y ingressou no serviço público por meio de concurso na década de 80, na área da saúde, no cargo de auxiliar de serviços gerais (ASG) em hospital público. Antes de ingressar no serviço público, Y trabalhou como empregada doméstica, vendedora e cozinheira.

Após alguns meses de trabalho, $\mathrm{Y}$ passou a trabalhar na copa do hospital, no preparo das bandejas com os alimentos e na distribuição das refeições para os pacientes. Nessa época, trabalhava em um sistema de plantões de 12 horas, folgando 48 horas (12h X 48h). 
De acordo com dados do prontuário, no final do primeiro ano de trabalho, $Y$ sofreu um acidente em serviço, escorregou no chão molhado e teve lesões no joelho. Em função desse acidente, a servidora foi readaptada, e passou a trabalhar como escriturária. Durante toda a sua vida laborativa, a servidora permaneceu exercendo a função de escriturária e apresentou artrose em várias partes do corpo e dores constantes na coluna. As dores que sentia a impediam de permanecer muito tempo em pé, e impossibilitaram que ela realizasse as funções de copeira.

Seis anos após esse acidente, $\mathrm{Y}$ permaneceu por alguns meses em licença para tratamento familiar (LTF), e, logo após, reduziu sua carga horária de trabalho para assistir um ente familiar que ficara totalmente dependente após um acidente. Ele residia com ela e precisava de ajuda em período integral para atividades da vida diária. Aproximadamente após três anos do usufruto da LTF, a servidora iniciou afastamentos do trabalho por diagnóstico de transtorno mental e comportamental - episódio depressivo, transtorno depressivo recorrente e transtorno de ansiedade -, permanecendo 300 dias não consecutivos em LTS intercalados com tentativas de retornar ao trabalho. Os dados do prontuário demonstram que, nesse período, além dos sintomas de tristeza, apatia, cansaço, insônia e irritabilidade, a servidora se queixava de dores pelo corpo, lombalgia e artrose.

Em um dos períodos de retorno ao trabalho, no ano 2005, Y vivenciou um evento estressor no contexto de trabalho. Um homem que desejava ser atendido no hospital, apesar de não possuir nenhuma consulta marcada, invadiu o espaço físico em que $Y$ trabalhava e que era restrito aos funcionários. Y esclareceu que era necessário agendamento prévio, por se tratar de atendimento ambulatorial, sendo que o agressor a intimidou com palavrões e ameaçou-a mostrando um revólver na cintura. Um colega de $Y$ conteve o agressor, que estava na iminência de agredi-la fisicamente. Após o episódio, no final do expediente, quando Y saia do local de trabalho, foi novamente interpelada pelo homem, sendo ameaçada de morte. $\mathrm{O}$ agressor mostrou-lhe novamente a arma, afirmando que iria segui-la. $Y$ retornou ao local de trabalho para buscar apoio, e os relatos dos colegas de trabalho evidenciam que ela se encontrava em extremo sofrimento psíquico.

Após esse evento, Y retornou ao trabalho, mas não conseguia manter a atenção concentrada nas atividades, não conseguia produzir, apresentava esquecimentos, sentiase ameaçada, acreditava que a qualquer momento o homem poderia segui-la e agredila. Y solicitou mudança de local de trabalho, mas seus superiores não compreenderam o motivo e não lhe concederam a remoção. Como Y não conseguia mais exercer as atividades laborativas, permaneceu em LTS por diagnóstico de transtorno mental e comportamental - episódio depressivo, transtorno depressivo recorrente, transtorno de ansiedade e transtorno misto de ansiedade e depressão - até o final do primeiro semestre de 2008, sendo posteriormente aposentada. A servidora sentia dores constantes na perna e na coluna e dificuldades na realização de atividades de vida diária; além disso, temia sair sozinha, e permanecia a maior parte do dia deitada ou sentada no sofá.

Com relação aos tratamentos realizados por Y, foi constatado que ela foi acompanhada pelos seguintes profissionais de saúde: ortopedista, endocrinologista, ginecologista, oftalmologista e psiquiatra, realizando tratamento psiquiátrico desde o nono ano de vida laboral no hospital até o momento da avaliação psicológica. A servidora afirmou que não havia realizado tratamento 
psicológico, pois não possuía condições financeiras para tal, e, em 2008, utilizava os seguintes psicofármacos: Rivotril, Zolpidem e Venlafaxina.

Na vistoria realizada no local de trabalho de $Y$, verificou-se que ela realizava atividades de atendimento ao público e atividades burocráticas. Analisando-se o seu posto de trabalho - escriturária de ambulatório hospitalar - observou-se que a maior parte de sua jornada de trabalho se caracterizava por fornecer informações presencialmente e via telefone, orientar pacientes sobre consultas, exames, cirurgias daquele setor específico e outros. Y também realizava as seguintes atividades: cadastrar pacientes na base de dados do sistema de informática, preparar as fichas de atendimento, anexar fichas de atendimentos aos prontuários, realizar solicitações de almoxarifado, farmácia, xerox, encaminhar e protocolar documentos, marcar e desmarcar cirurgias, guardar e preparar os prontuários, atender ligações telefônicas e dar baixa em todos os procedimentos realizados no final do expediente.

Verificou-se que o servidor que atua no referido posto de trabalho está em contato direto e constante com o público, funcionando como linha de frente da instituição ao ouvir as reclamações e os desabafos dos usuários a respeito do tempo de espera para agendamento de consultas, da falta de vagas para atendimento e dos descontentamentos com o atendimento recebido. A maior parte dos conteúdos das interações comunicacionais com os usuários é relacionada à sua insatisfação. Em alguns momentos, o servidor atende simultaneamente alguém no balcão, verificando a situação no sistema do computador, e outra pessoa no telefone. De acordo com a fila de pacientes, as chamadas telefônicas, as exigências da equipe médica e outras demandas de trabalho tornam o ritmo do trabalho intenso.

Nas entrevistas realizadas no local de trabalho, chefias e colegas afirmam que, às vezes, acontecem situações de algum paciente insultar e perturbar o servidor no posto de trabalho, ameaçando-o verbalmente. Quando isso ocorre, o procedimento recomendado consiste em chamar o vigilante e/ou polícia. Geralmente, nessas ocasiões, o paciente invade o acesso restrito dos funcionários, entrando no local onde ficam os escriturários e os demais servidores.

Segundo Jacques (2007), a investigação diagnóstica para o estabelecimento do nexo causal entre a atividade laborativa e os distúrbios mentais apresentados pelo trabalhador impõe a anamnese ocupacional como instrumento prioritário. Nesta investigação, tenta-se entender as associações entre as condições de vida e de trabalho e o aparecimento, a frequência ou a gravidade da psicopatologia. As diversas questões a serem analisadas pela anamnese ocupacional necessitam de uma ou mais entrevistas com o próprio trabalhador, os familiares, chefias e colegas de trabalho. Na avaliação psicológica, testes psicológicos poderão ser utilizados, como também pode-se aproveitar o ensejo para identificar alterações intelectuais, sensoriais, de memória e aprendizagem, espaciais e de personalidade do trabalhador.

Os resultados principais indicaram que os riscos psicossociais são fatores que deterioram as relações de trabalho, geram sofrimento, adoecimento ocupacional, incapacidade e disfunção organizacional, além de decorrências com benefícios como a caracterização de acidente em serviço, licença para tratamento de saúde e aposentadoria, além de custos humanos e financeiros às organizações do Poder Executivo estadual. 


\section{Discussão}

Avaliar os FRPT buscando suporte em dados documentais de um servidor público foi o desafio deste trabalho; destaca-se que pesquisas evidenciam as cargas de valores, as preferências, os interesses e os princípios do pesquisador, assim, aduz-se que sua visão de mundo influencia sua compreensão e suas abordagens. Os efeitos dos FRPT variam de pessoa para pessoa, de acordo com o tipo de personalidade e a predisposição do indivíduo em lidar com as demandas do seu trabalho, mas os efeitos indesejáveis decorrentes desses fatores de risco dificilmente desaparecem.

Os fatores individuais (personalidade, pessoas mais vulneráveis/idiossincrasias, dificuldade de adaptação e de gerenciamento do estresse, insatisfação com o trabalho), os fatores organizacionais (condições e organização do trabalho, ambiguidade ou imprecisão quanto à tarefa a realizar, diferenças na divisão da carga de trabalho, ritmos intensos de produção, densidade de tarefas, exigências físicas e mentais decorrentes da atividade) e os fatores do contexto social (exigência de produtividade, metas abusivas) podem facilitar o surgimento do adoecimento e da incapacidade laboral.

De acordo com Borsoi (2007), quando se trata de acidente de trabalho típico, é fácil identificar o agente que ocasionou o dano, mas, em se tratando de doenças profissionais ou relacionadas ao trabalho, essa associação nem sempre é diretamente visível ou concreta, sendo complexo o reconhecimento, de forma objetiva, dos determinantes da doença. E, sem o devido reconhecimento, o trabalhador não percebe os direitos advindos de sua condição de acidentado.

A revisão de literatura apresentada demonstra que os FRPTs repercutem na saúde física e mental dos trabalhadores, podendo ocasionar sofrimento, vivências de desconforto e malestar, estresse ocupacional, patologias diversas e incapacidade. Por meio do estudo de caso apresentado, relativo à caracterização de acidente em serviço, observou-se que os FRPTs aos quais $Y$ esteve submetida geraram impactos em sua saúde, ocasionando doença relacionada ao trabalho e aposentadoria por invalidez.

Em relação ao posto de trabalho, as atividades de escriturária envolvem tarefas que implicam carga de trabalho cognitiva e psíquica. Segundo Cruz (2002), a carga de trabalho cognitiva se refere a atenção, concentração, memória, raciocínio e tomada de decisões. Y utilizava todas essas funções psicológicas no atendimento e na orientação aos pacientes presencialmente e via telefone, e na realização das demais atividades burocráticas.

A carga de trabalho psíquica diz respeito ao sofrimento relacionado às demandas das relações interpessoais com colegas, chefias e ao atendimento direto aos pacientes bem como à mediação de conflitos no contexto de trabalho. Verificou-se que a servidora estava constantemente exposta ao sofrimento dos pacientes, situação característica do trabalho em instituições hospitalares, sendo essa exposição agravada pelas condições e pela organização do trabalho. Y, em seu posto de trabalho, funcionava como depositária das frustrações e das reclamações dos pacientes. Além do incidente ocorrido em 2005, em que a servidora foi ameaçada com arma, os demais servidores que continuam atuando no posto de trabalho relatam a ocorrência de outras situações em que usuários fazem ameaças e invadem o espaço restrito aos funcionários. Em algumas situações, foi necessário mediar conflitos entre pacientes em contextos em que um paciente alegava que o outro estava obtendo vantagens em detrimento dos seus direitos. 
A sobrecarga de $\mathrm{Y}$ com relação à jornada de trabalho também deve ser considerada, pois os seus turnos, durante 12 dias do mês, eram das $7 \mathrm{~h}$ até às $19 \mathrm{~h}$, ou seja, trabalhava 12 horas. Nos demais dias úteis do mês, o equivalente a 8 dias, trabalhava seis horas. Ressalta-se que, além dessas horas de trabalho no hospital, a servidora possuía atividades inerentes ao contexto familiar e doméstico.

A situação de $Y$ reflete o que ocorre com os servidores da área da saúde, que realizam ampliação da jornada de trabalho por horas-plantão. Do ponto de vista do gestor público, essa estratégia pode ser utilizada com a finalidade de minimizar as dificuldades ocasionadas pela falta de profissionais em um determinado local de trabalho, além de diminuir os encargos trabalhistas implicados na contratação de profissionais em número suficiente e adequado para as demandas sociais de atendimento à saúde. Para os servidores, as horas-plantão funcionam como forma de melhorar a renda familiar. Essa estratégia, entretanto, representa sobrecarga continuada e dificuldade de avaliação da real necessidade de contratar novos servidores.

$\mathrm{Y}$ vivenciou dois acidentes em serviço ao longo de sua vida laborativa. O primeiro deles, logo no começo de sua trajetória profissional, foi caracterizado por uma queda no chão molhado, ocasião em que machucou o joelho. É importante ressaltar que, a partir desse acidente, $Y$ passou a desenvolver dores e sintomas típicos de doenças do sistema osteomuscular, que culminaram em LTSs e na readaptação para a realização de outras funções. Como não podia mais exercer as atividades de copeira, foi readaptada para a função de escriturária.

Considerando que a servidora realizou concurso público para ASG, pode-se questionar até que ponto ela teria condições de realizar a função de escriturária. Essa função exige conhecimentos e habilidades diferentes, principalmente no que concerne a carga de trabalho psíquica, a capacidade para atender as demandas e as frustrações dos pacientes que, muitas vezes, não conseguem ser atendidos pelo Serviço Único de Saúde (SUS) da forma como gostariam. Será que essa sobrecarga psíquica, aliada a uma vulnerabilidade preexistente da servidora ao transtorno depressivo, outras intercorrências ocorridas em sua vida privada - familiar doente que precisava de cuidados constantes problemas osteomusculares e dores constantes pelo corpo a conduziram para um quadro depressivo?

Quando tentava retornar para as atividades laborativas, sofreu outro acidente em serviço: foi agredida por um homem descontrolado por não conseguir uma consulta no momento em que precisava. O fato de ter sido ameaçada com uma arma por duas vezes, uma no posto de trabalho e outra no ambiente externo ao hospital, tratando-se de ameaças de morte, acarretou prejuízos nas suas funções psicológicas, dificultando a realização das atividades laborativas e o desempenho das atividades diárias.

$\mathrm{Na}$ caracterização do segundo acidente em serviço de $\mathrm{Y}$, o nexo causal do adoecimento com o trabalho foi realizado, tendo em vista o episódio da agressão sofrida - fato esse comprovado por meio de testemunhas bem como sua vivência em relação ao fato e as repercussões na sua saúde mental. Y já apresentava afastamentos compatíveis com transtorno depressivo, e permanecia em LTS por esse motivo. Mas, de acordo com a classificação de Schilling (1984), o trabalho pode ocasionar um distúrbio latente, ou potencializar uma patologia preexistente.

Constata-se que $Y$ esteve exposta a vários FRTPs durante toda a sua vida laborativa: sobrecarga de trabalho psíquica e cognitiva, 
violência no ambiente de trabalho, ritmo intenso e sobrecarga quantitativa de trabalho, considerando também o contexto doméstico, e falta de compreensão dos seus superiores. Analisando-se o evento sofrido e a possibilidade de o trabalho exacerbar uma doença já existente, estabeleceu-se a relação de causalidade entre a doença e o trabalho. Ressalta-se que, no Decreto no 3.048 (1999), do Ministério da Previdência e Assistência Social, a depressão aparece como uma doença relacionada ao trabalho, ou seja, fatores de riscos psicossociais no trabalho podem prejudicar a saúde mental do trabalhador, ocasionando um quadro depressivo.

O caso de $Y$ reflete a situação de servidores públicos da área da saúde no que se refere à exposição aos FRTPs, bem como os danos implicados na ausência de ações de prevenção da saúde no trabalho e no tratamento de saúde, que foi reduzido a uma concepção biomédica do processo saúde-doença. Segundo Cooper e Cartwright (2002), a prevenção dos fatores de risco psicossociais baseia-se na prevenção do estresse, e pode ser classificada em prevenção primária, secundária e terciária.

A prevenção primária refere-se às ações dirigidas a reduzir ou a eliminar os fatores do estresse, buscando a sua origem, promovendo um meio ambiente saudável e solidário. A prevenção secundária implica a detecção e o tratamento precoce de problemas físicos emocionais por meio da sensibilização dos trabalhadores e da promoção de estratégias de controle do estresse. A terciária consiste na reabilitação e na recuperação das pessoas que sofrem problemas de saúde produzidos pelo estresse.

Guimarães descreve uma série de medidas de controle para a redução dos FRPT: realização de capacitação, monitoramento de trabalho em turnos e de horas extras, motivação das equipes de trabalho, estabelecimento de uma comunicação adequada e busca de soluções, redução da monotonia das tarefas, estipulação da sobrecarga de trabalho razoável, prazos e demandas adequadas e de acordo com as capacidades dos trabalhadores.

A NTP no 604 aborda algumas medidas de prevenção dos fatores de riscos psicossociais baseadas no modelo demanda-controle-apoio social de acordo com as três dimensões: a) demandas: agir com transparência na distribuição das tarefas, estabelecer a carga de trabalho de acordo com o conteúdo quantitativo e qualitativo da tarefa, considerar as capacidades e recursos da pessoa, colocar pessoas suficientes nas unidades de trabalho, estabelecer mecanismos que permitam ao trabalhador tomar decisões sobre o seu próprio ritmo, quantidade de trabalho, tempo necessário e pausas necessárias; b) controle: promover a tomada de decisões dos trabalhadores sobre os métodos e ordens das tarefas, proporcionar tarefas significativas, que tenham sentido, criar oportunidades para a autorrealização e o desenvolvimento profissional, oportunizar condições de aprendizagem e de utilização de novas habilidades, potencializar o uso das capacidades mentais no trabalho, evitar a excessiva burocratização das tarefas; c) apoio social: estimular o trabalho em equipe e a comunicação, estabelecer objetivos em equipe, criar espaços de reflexão e de compartilhamento de dúvidas, valorizar as reuniões de trabalho, estabelecer mecanismos de recompensa e de reconhecimento no trabalho, estabelecer medidas que impeçam as condutas competitivas entre os trabalhadores e proibir explicitamente qualquer forma de assédio dentro da organização.

No Brasil, percebe-se uma fragilidade em legislações e normas específicas para a prevenção dos FRPT, diferentemente de 
outros países da comunidade europeia. As normas regulamentadoras do Ministério do Trabalho e Emprego não priorizam os riscos psicológicos e sociais, apenas os abordam de forma indireta por meio da NR no 17 , que versa sobre os fatores ergonômicos.

Em Santa Catarina, com a criação da GESAO, iniciou-se a reflexão sobre as formas de instituir ações sistematizadas e descentralizadas de saúde ocupacional de acordo com as peculiaridades e as necessidades de cada órgão do Poder Executivo do Estado. A equipe da GESAO elaborou o Programa Estadual de Saúde Ocupacional do Servidor, que foi transformado na Lei no14.609 (2009). Esse programa concebe diretrizes e normas relacionadas à gestão e à execução de ações de saúde ocupacional para os servidores catarinenses, com o objetivo de melhorar as condições do ambiente, da organização e das relações de trabalho, por meio da atuação de equipes multiprofissionais descentralizadas em cada órgão do Estado.

Nesse programa, o art. 2, inciso III, considera como riscos ocupacionais os "(...) físicos, químicos, biológicos, ergonômicos, mecânicos, psicológicos e sociais". A inclusão dos riscos psicológicos e sociais nesse programa representa ampliação e inovação na maneira de se conceber a saúde ocupacional. Além dos riscos previstos pelas normas regulamentadoras do Ministério do Trabalho e Emprego, os aspectos psicológicos e sociais também são considerados como fatores de risco no processo saúde-doença do servidor (Serafim, 2009).

Tendo em vista a necessidade de os órgãos do Poder Executivo estadual desenvolverem ações de forma equânime e de acordo com as necessidades e as peculiaridades de cada instituição, principalmente os relativos aos riscos psicológicos e sociais, um grupo de representantes de várias Secretarias de
Estado elaborou um capítulo do Decreto no 2.709 (2009) que institui o Manual de Saúde Ocupacional do Servidor Público, intitulado Programa de Prevenção de Riscos Psicológicos e Sociais para os Servidores Públicos Estaduais de Santa Catarina.

Esse decreto estabelece os parâmetros mínimos e as diretrizes gerais para a implementação desse programa por parte dos órgãos do Poder Executivo estadual. Há previsão de que o programa seja desenvolvido por psicólogo e assistente social da equipe multiprofissional de saúde ocupacional, sendo que, em função da complexidade da avaliação desses riscos, outros profissionais dessa equipe poderão participar. A periodicidade prevista para a realização desse programa é bienal, ou sempre que os profissionais responsáveis julgarem necessário, de forma contínua e sistemática, de acordo com as necessidades e as peculiaridades de cada estabelecimento dos órgãos da administração pública estadual.

\section{Considerações finais}

Destarte, por tratar-se de um estudo de caso, não é possível generalizar os aspectos encontrados na pesquisa documental desse sujeito e estendê-los à população em geral, o que consiste uma das limitações deste trabalho. Pode-se afirmar que os FRPT compreendem toda condição e/ou exigência inerente ou relacionada ao trabalho que produza efeitos negativos ou agravos à saúde nas dimensões perceptiva, cognitiva, afetiva, volitiva e comportamental do trabalhador e que prejudiquem as relações socioprofissionais, originando vivências de mal-estar e de sofrimento individual e coletivo.

O estudo de caso apresentado com base em procedimentos de perícia psicológica para a caracterização de acidente em serviço ou doença relacionada ao trabalho permitiu 
inferir algumas evidências de que a exposição contínua de servidores aos FRPT pode levar ao adoecimento e à incapacidade. A servidora esteve exposta aos vários tipos de FRPT e vivenciou sobrecarga de suas capacidades de adaptação, o que ocasionou o comprometimento da sua saúde mental e a impossibilidade de retorno ao trabalho.

Os estudos apresentados demonstram que diversas práticas podem ser adotadas nas organizações pelos gestores para a prevenção desses fatores de risco. No que concerne aos servidores públicos catarinenses, a Lei no 14.609 (2009) já representa um avanço dos dispositivos legais referentes à saúde do trabalhador do serviço público. O capítulo do decreto referente ao Programa de Prevenção de Riscos Psicológicos e Sociais aborda os fatores de risco psicossociais do trabalho de forma contundente. Esse dispositivo via legislação ainda é recente no Estado, entretanto, urge a conscientização e a aplicação das diretrizes preconizadas nos órgãos do Poder Executivo estadual para que sejam realizadas a promoção da saúde e a prevenção dos FRPT.

Não foi possível detectar, no prontuário analisado, a amplitude dos FRPT, necessitandose de aprofundamento desses aspectos em novos estudos. Considerando-se que o processo de avaliação dos FRPT implica o uso de instrumentos (escalas, inventários), espera-se complementar a pesquisa obtendose um padrão de medição formalizado que possibilite representar adequadamente a realidade do tema. A escala poderá ser desenvolvida, validada e incorporada como instrumento de aplicação prática e rápida aos demais modelos de avaliação pericial e de saúde ocupacional.

\section{Alessandra da Cruz Serafim}

Psicóloga, Servidora da Secretaria de Estado da Administração, Especialista em Psicologia Organizacional e do Trabalho. E-mail: aleserafim@hotmail.com

\section{Izabel Carolina Martins Campos}

Assistente Social, Servidora da Secretaria de Estado da Administração e Doutora em Engenharia de Produção pela Universidade Federal de Santa Catarina.

E-mail: izacarol@gmail.com

\section{Roberto Moraes Cruz}

Psicólogo, Docente da Universidade Federal de Santa Catarina, Doutor em Engenharia de Produção.

E-mail: fatorhumano.ufsc@gmail.com

Michelli Moroni Rabuske

Psicóloga, Servidora do Tribunal de Justiça de Santa Catarina e Doutora em Psicologia pela Universidade Federal de Santa Catarina.

E-mail: michelli_rabuske@yahoo.com.br

Endereço para envio de correspondência:

Rua: Tenente Silveira, 570, apto 502, Centro, Florianópolis, Santa Catarina, SC - Brasil. CEP 88010-301 


\section{Referências}

Araujo, T. M., Aquino, E., Menezes, G., Santos, C. O., \& Aguiar, L. (2003). Aspectos psicossociais do trabalho e distúrbios psíquicos entre trabalhadoras de enfermagem. Rev. Saúde Pública (online), 37(4), 424-433. doi: 10.1590/S003489102003000400006. Recuperado em 29 de janeiro, 2011 de http://www.scielosp.org/scielo.php?script=sci arttext\&pid=S0034-89102003000400006\&lng=en\&nrm $=$ iso.

Benevides-Pereira, A. M. (2002). Burnout: o processo de adoecer pelo trabalho. In A. M. Benevides-Pereira, (Org.), Burnout: quando o trabalho ameaça o bem-estar do trabalhador (pp. 21-91). São Paulo: Casa do Psicólogo.

Borsoi, I. C. F. (2007). Da relação entre trabalho e saúde à relação entre trabalho e saúde mental. Psicol. Soc. (online), 19(Spec.),103-111. doi: 10.1590/S010271822007000400014. Recuperado em 25 de janeiro, 2011 de http://www.scielo.br/scielo.php?script=sci arttext\&pid $=$ S0102-71822007000400014\&lng=en\&nrm =iso.

Braga, L. C. de, Carvalho, L. R. de, \& Binder, M. C. P. (2010). Condições de trabalho e transtornos mentais comuns em trabalhadores da rede básica de saúde de Botucatu (SP). Ciênc. Saúde Coletiva (online), 15(Suppl.1), 1585-1596. doi: 10.1590/S1413-81232010000700070. Recuperado em 29 de janeiro, 2011 de http://www.scielo.br/scielo.php?script=sci arttext\&pid $=$ S1413-81232010000700070\&lng =en\&nrm $=\bar{i}$ so. ISSN 1413-8123.

Brasil. Ministério da Saúde. Resoluções do Conselho Nacional de Saúde: 196/96; 251/97; 292/99. Recuperado em 13 de Junho, 2012 de: http://www.conselho.saude.gov.br/ Brasil

Ministério da Saúde (2000)

Cabana, M. C. F. de L., Ludemir, A. B., Silva, É. R., Ferreira, M. L. L., \& Pinto, M. E. R. (2007). Transtornos mentais comuns em médicos e seu cotidiano de trabalho. Rev. Bras. Psiquiatr. (online), 56(1), 33-40. doi: 10.1590/S004720852007000100009. Recuperado em 29 de janeiro, 2011 de http://www.scielo.br/scielo.php?script=sci_arttext\&pid= 0047-2085.

Campos, I. C. M. (2006). Diagnóstico de transtornos mentais e comportamentais e relação com o trabalho de servidores públicos estaduais. Dissertação de mestrado. Programa de Pós-Graduação em Psicologia, Universidade Federal de Santa Catarina, Florianópolis, SC.

Cartwright, S., \& Cooper, C. L. (2002). Resumen de las estrategias generales de prevención y control in factores psicosociales y de organización. In Enciclopédia de Salud y Seguridad en el Trabajo. Recuperado em 10 abril, 2009, de http://mtas.es/ insht/EncOIT/index.htm

Conselho Federal de Psicologia. Resolução no 16, de 20 de dezembro de 2000 (2000, 20 de dezembro). Dispõe sobre a realização de pesquisa em Psicologia com seres humanos. Recuperado em 13 de Junho, 2012 de _http://www.pol.org.br/ pol/export/sites/default/pol/legislacao/legislacaoDocumentos/ resolucao2000_16.pdf. (2000, 20 de dezembro) depois de Conselho Federal de Psicologia.

Cruz, R. M. (2002). Saúde, trabalho e psicopatologias. In B. W. Aued (Org.), Traços do trabalho coletivo (pp. 201- 233). São Paulo: Casa do Psicólogo.

Cunha, J. B., Blank, V. L. G., \& Boing, A. F. (2009). Tendência temporal de afastamento do trabalho em servidores públicos (1995-2005). Rev. Bras. Epidemiol. (online), 12(2), 226-236. doi: 10.1590/S1415-790X2009000200012. Recuperado em 28 de Janeiro, 2011 de http://www.scielosp.org/scielo. php?script $=$ sci_arttext $\&$ pid $=$ S1415-790X2009000200012\& lng $=$ en\&nrm = iso. ISSN 1415-790X.

Dejours, C., \& Abdoucheli, E. (1993). Itinerário teórico em psicopatologia do trabalho. In C. Dejours, E. Abdoucheli \& C. Jayet, Psicodinâmica do trabalho: contribuições da escola dejouriana à análise da relação prazer, sofrimento e trabalho (pp. 119-145). (M. I. S. Betiol et al., trad.) São Paulo: Atlas (Trabalho original publicado em 1990).

Decreto n. 1.456, de 23 de dezembro de 1996. (1996, 23 de dezembro). Dispõe sobre a assistência aos servidores públicos estaduais, em decorrência de acidentes em serviço e doença profissional, nos órgãos da administração direta, autarquias e fundações do Poder Executivo. Florianópolis, SC: Diário Oficial do Estado

Decreto n. 2.709, de 27 de outubro de 2009. (2009, 27 de outubro). Institui o Manual de Saúde Ocupacional do Servidor Público, no âmbito da administração pública estadual direta e indireta. Florianópolis, SC: Diário Oficial do Estado.

Decreto n. 6.042, de 12 de fevereiro de 2007. (2007, 12 de fevereiro). Altera o Regulamento da Previdência Social, aprovado pelo Decreto no 3.048, de 6 de maio de 1999, disciplina a aplicação, acompanhamento e avaliação do Fator Acidentário de Prevenção - FAP e do Nexo Técnico Epidemiológico, e dá outras providências. Brasília, DF: Diário Oficial da União..

Ferreira, M. C., \& Mendes, A. M. (2003). Trabalho e riscos de adoecimento: o caso dos auditores-fiscais da Previdência Social Brasileira. Brasília, DF: Ler, Pensar, Agir.

Guimarães, L. A. M. (2006). Fatores psicossociais de risco no trabalho. Artigo do $2^{\circ}$ Congresso Internacional sobre Saúde Mental no Trabalho, Goiânia, GO. Recuperado em 10 janeiro, 2009, de http://www.prt18.mpt.gov.br/eventos/2006/ saude_mental/anais/artigos.htm.

Jacques, M. da G. C. (2003). Abordagens teórico-metodológicas em saúde/doença mental \& trabalho. Psicol. Soc. (online), 15(1), 97-116. doi: 10.1590/S0102-71822003000100006. Recuperado em 25 de janeiro, 2011 de http://www. scielo.br/scielo.php?script $=$ sci_arttext $\&$ pid $=$ S0102$71822003000100006 \& \operatorname{lng}=\mathrm{en} \& \mathrm{nrm}=$ iso. ISSN 0102-7182.

Jacques, M. da G. (2007). O nexo causal em saúde/doença mental no trabalho: uma demanda para a psicologia. Psicol. Soc. (online). 19(Esp.), 112-119. doi: 10.1590/ S0102-71822007000400015. Recuperado em 24 de janeiro, 2011 de http://www.scielo.br/scielo.php?script=sci_ arttext\&pid =S0102-71822007000400015\&lng=en\&nrm =iso.

Karasek, R. (2002). El modelo de demandas-control: enfoque social, emocional y fisiológico del riesgo de estres y desarrollo de comportamientos activos in factores psicosociales y de organización. In Enciclopédia de Salud y Seguridad en el Trabajo. Recuperado em 10 abril, 2009, de http://mtas.es/ insht/EncOIT/index.htm

Lei $n^{\circ}$. 14.609, de 07 de janeiro de 2009. (2009, 07 de janeiro). Institui o Programa Estadual de Saúde Ocupacional do Servidor Público e estabelece outras providências. Florianópolis, SC: Diário Oficial do Estado. 


\section{Referências}

Lei $n^{\circ}$ 11.430, de 26 de dezembro de 2006. (2006, 27 de dezembro). Altera as Leis no8.213, de 24 de julho de 1991, e no 9.796, de 5 de maio de 1999, aumenta o valor dos benefícios da previdência social, e revoga a Medida Provisória no 316, de 11 de agosto de 2006; dispositivos das Leis no 8.213, de 24 de julho de 1991, no 8.444, de 20 de julho de 1992, e da Medida Provisória no 2.187-13, de 24 de agosto de 2001, e a Lei no 10.699, de 9 de julho de 2003. Brasília, DF: Diário Oficial da União.

Levi, L. (2002). Factores psicosociales, estres y salud in factores psicosociales y de organización. In Enciclopédia de Salud y Seguridad en el Trabajo. Recuperado em 10 abril, 2009, de http://mtas.es/insht/EncOIT/index.htm

Ministério da Previdência e Assistência Social (1999, 07 de maio). Decreto n. 3.048, de 06 de maio de 1999.. Aprova o regulamento da Previdência Social, e dá outras providências. Brasília, DF: Autor.

Ministério da Saúde do Brasil. OPAS/Brasil. (2001). Doenças relacionadas com o trabalho: diagnóstico e condutas Manual de Procedimentos para Serviços e Saúde. Brasília, DF. Recuperado em 13 fevereiro, 2007, de http://bvsms.saude. gov.br/bvs/publicacoes/partes/doencas_trabalho1.pdf.

Ministério do Trabalho e dos Assuntos Sociais da Espanha. (1994). Instituto Nacional de Seguridade e Higiene do Trabalho. Norma Técnica de Prevenção - NTP 443, 603, 604.

Nascimento Sobrinho, C. L. et al. (2006). Condições de trabalho e saúde dos médicos em Salvador, Brasil. Rev. Assoc. Med. Bras. (online), 52(2), 97-102. doi: 10.1590/ S0104-42302006000200019. Recuperado em 29 de janeiro, 2011 de <http://www.scielo.br/scielo.php?script =sci arttext\&pid $=$ S0104-42302006000200019\&Ing $=$ en\&nrm $=$ iso $>$.

Noronha, A. P. P., \& Fernandes, D. C. (2007). Estresse laboral e raciocínio inferencial: um estudo correlacional. Psicol.: Ciênc. e Prof. (online), 27(4), 596-607. Recuperado em 24 de janeiro, 2011 de <http://pepsic.bvsalud.org/scielo.php?script=sci arttext\&pid $=$ S1414-98932007001200003\&lng $=$ pt\&nrm $=$ iso $>$.

Oliveira, S. G. (2002). Agressões à saúde do trabalhador. In Proteção jurídica à saúde do trabalhador (pp.65-98). São Paulo: LTR

Oficina Internacional del Trabajo. (1986). Factores psicosociales en el trabajo. Naturaleza, incidencia y prevención. Ginebra: OIT.

Paschoal, T., \& Tamayo, A. (2004). Validação da escala de estresse no trabalho. Estud. Psicol. (online), 9(1), 45-52. doi: 10.1590/S1413-294X2004000100006. Recuperado em 27 de janeiro, 2001 de <http://www.scielo.br/scielo. php?script $=$ sci_arttext\&pid $=$ S1413-294X2004000100006 $\& \operatorname{lng}=$ en\&nrm $=$ iso $>$.

Pinho, P. S., \& Araújo T. M. (2007). Trabalho de enfermagem em uma unidade de emergência hospitalar e transtornos mentais. Revista de Enfermagem da UERJ, 15(3), 329-336.

Resolução INSS/DC $n^{\circ}$ 10, de 23 de dezembro de 1999. (2000, 20 de abril). Aprova os protocolos médicos, com alterações realizadas pela Coordenação-Geral de Benefícios por Incapacidade da Diretoria de Benefícios, e dá outras providências. Brasília, DF. Recuperado em 25 abril, 2009, de http://www81.dataprev.gov.br/sislex/paginas/72/INSSDC/1999/10.htm.
Santos, L. C., Goulart Junior, E., Canêo, L. C., Lunardelli, C. F., \& Carvalho, P. L. T. de. (2010). Psicologia e profissão: neurose profissional e a atuação do psicólogo organizacional frente à questão. Psicol.: Ciênc. e Prof. (online), 30(2), 248-261. Recuperado em 24 de janeiro, 2011 de <http://pepsic. bvsalud.org/scielo.php?script $=$ sci_arttext $\&$ pid $=\mathrm{S} 1414$ $98932010000200003 \& \operatorname{lng}=$ en\&nrm $=$ iso $>$.

Sauter, S. L., Hurrel J. R., J. J., Murphy, L. R., \& Levi, L. (2002). Factores psicosociales y de organización in factores psicosociales y de organización. In Enciclopédia de Salud y Seguridad en el Trabajo. Recuperado em 10 abril, 2009, de http://mtas.es/insht/EncOIT/index.htm.

Secco, I. A. de O., Robazzi, M. L. do C. C., Souza, F. E., Alves de, \& Shimizu, D. S. (2010). Cargas psíquicas de trabalho e desgaste dos trabalhadores de enfermagem de hospital de ensino do Paraná, Brasil. SMAD, Rev. Eletrônica Saúde Mental Álcool Drog. (Ed. port.) (online), 6(1), 1-17. Recuperado em 29 de janeiro, 2011 de <http://pepsic.bvsalud.org/scielo. php?script=sci_arttext\&pid=S1806-69762010000100016\&ln $\mathrm{g}=\mathrm{pt} \& \mathrm{nrm}=\mathrm{iso}>$.

Schibuola, T. (2005, setembro). Você em equilíbrio: doenças do trabalho. Revista Você S. A., 89, 74-78.

Schilling, R. S. F. (1984). More effective prevention in occupational health practice. Journal of the Society of Occupational Medicine, 39, 71-79.

Secretaria de Estado da Administração. (2008). Boletim estatístico de saúde do servidor. (J. C. C. B. Cunha \& L. S. Lucca, orgs.). Florianópolis, SC: Diretoria de Gestão Documental.

Serafim, A. (2009). Desafios na gestão de políticas públicas de saúde ocupacional: elaboração e implantação do Programa Estadual de Saúde Ocupacional do Servidor Público de Santa Catarina. In II Congresso Consad de Gestão Pública, Brasilia, DF: Conselho Nacional de Secretários de Estado de Administração. (Painel 12: Gestão Políticas Públicas de Saúde Ocupacional).

Trivelato, G. C. (1998). Metodologias de reconhecimento e avaliação qualitativa de riscos ocupacionais. São Paulo: Fundacentro.

Yin, R. K. (2005). Estudo de caso: planejamento e métodos (3a ed.). Porto Alegre: Bookman. 